\title{
LA PINTURA ROMÁNICA EN EL ANTIGUO REINO DE ARAGÓN. INTERCAMBIOS ESTILÍSTICOS E ICONOGRAFICOS
}

M. ${ }^{a}$ Carmen Lacarra Ducay

Universidad de Zaragoza*

* El presente trabajo se ha realizado en el marco del Grupo de Investigación Consolidado: Artífice (Patrocinio y circulación artística y musical en Aragón en las Edades Media y Moderna) del Gobierno de Aragón. 

En la segunda mitad del siglo xx, comenzaron a salir a la luz importantes conjuntos de pintura mural románica en el Alto Aragón que permitieron hablar de una escuela pictórica aragonesa. Obras dispersas por diferentes lugares de las diócesis de Huesca, Jaca y Barbastro, que no dejaron de llamar la atención de los investigadores españoles y extranjeros, configurando un nuevo mapa de la geografía artística peninsular.

Recientes hallazgos de pinturas murales románicas dotadas de documentación han ayudado a profundizar en estos estudios, estableciendo nuevas relaciones entre los diversos talleres artísticos aragoneses de la primera mitad del siglo XII.

Para nuestro análisis hemos seleccionado algunas obras de pintura mural y sobre tabla de origen aragonés, de las que las más antiguas coinciden en el tiempo con la prelatura en Compostela de don Diego Gelmírez (1100-1140), figura clave en la historia política y cultural de Galicia.

1.

El primer gran conjunto de pintura mural románica corresponde a la localidad de Bagüés, lugar con ayuntamiento de la provincia de Zaragoza que pertenece al partido judicial de Ejea de los Caballeros desde 1965 y a la diócesis de Jaca desde 1971. Bagüés habría sido donado al monasterio de San Juan de la Peña en tiempos del rey Ramiro I (1035-1064) con otras diversas propiedades dispersas por los territorios más o menos cercanos, villas, iglesias $\mathrm{y}$ «monasteriolos» ${ }^{1}$, con

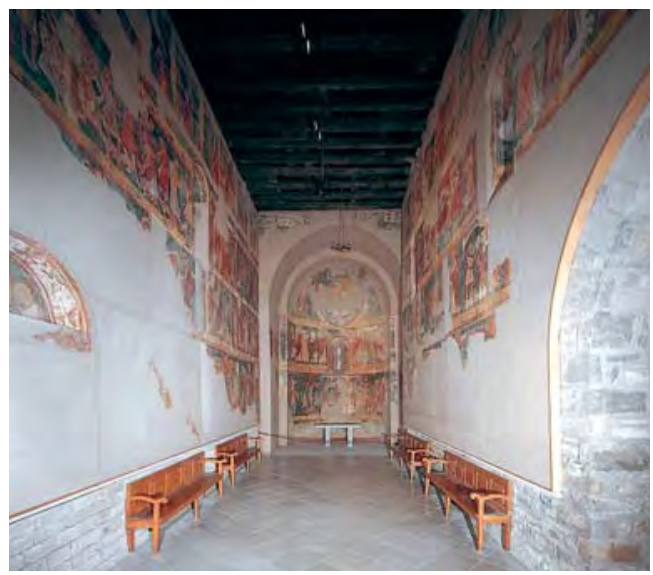

Vista general de las pinturas murales de Bagüés (Zaragoza). Museo Diocesano de Jaca (Huesca).

1 Diminutivo de monasterios para referirse en plural a la habitación de eremita, en algunos casos rupestres, frecuentes en Aragón y Navarra en la segunda mitad del siglo xi, como consecuencia del fervor monástico de la época. A. Durán Gudiol (1991). 
sus derechos y términos. Durante el reinado de Sancho Ramírez (1064-1094), su iglesia parroquial pasaría a ser priorato de San Juan de la Peña en tiempos del abad Aquilino (1071), por donación del obispo Sancho de Aragón (1058-1075)².

En las últimas décadas del siglo XI, hay que fijar la construcción de la iglesia parroquial de los santos Julian y Basilisa de Bagüés, dada la generosidad manifestada por el rey aragonés Sancho Ramírez (1064-1094) con el monasterio pinatense, que tendría continuidad con su hijo y sucesor, Pedro I de Aragón y Navarra $(1094-1104)^{3}$.

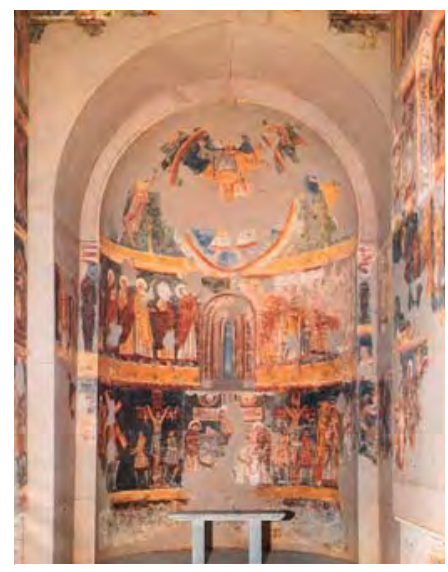

Bagüés, vista general del ábside. Museo Diocesano de Jaca (Huesca).

La iglesia, edificada a las afueras de la población y próxima al cementerio, fue construida en origen con una sola nave de gran altura y una cabecera semicircular que recibe bóveda de cuarto de esfera precedida de tramo cubierto con bóveda de medio cilindro. La nave se cubría con armadura de madera para soportar el tejado a dos aguas. Realizada en mampostería irregular, se decora en el exterior con arquillos ciegos que apean alternativamente en ménsulas y pilastras de tipo lombardo, como pervivencia de elementos del primer románico, visibles también en otros puntos de la geografía aragonesa.

El acceso al edificio se realizaba por el lado norte o del evangelio a través de una puerta de arco de medio punto carente de decoración escultórica. Los vanos de iluminación, de medio punto y de derrame interno, se ubicaban uno en el muro central del ábside, para la iluminación del altar principal, y los cuatro restantes en los muros laterales de la nave, de los que tres se sitúan en el lado derecho o de la epístola, y el último, de menor tamaño, en el centro del lado norte o del evangelio, próximo a la puerta de ingreso al templo.

En época posterior se construyó, a los pies del edificio, la torre campanario, de planta cuadrada y piedra sillar, insertada en gran parte en el interior de la nave, en

2 A. I. Lapeña Paul (1989).

3 Entonces tiene lugar una gran actividad constructiva en el propio monasterio con la edificación de la iglesia superior, consagrada el 4 de diciembre de 1094, y cuando se multiplican las donaciones por parte del alto clero y de la nobleza, habida cuenta su condición de Panteón Real. 
el lugar donde pudo estar en origen la puerta de ingreso principal que hubo que sacrificar. Posiblemente, en esta nueva fase constructiva — que algunos autores fijan en el siglo Xvi o incluso después - se edificó una segunda nave de menores dimensiones, que se adosa al lado meridional. Ambas se comunican a través de sendos arcos de medio punto practicados en el muro de la iglesia primitiva, hecho que afectó al conjunto de pintura mural del lado derecho o de la epístola ${ }^{4}$.

La decoración mural de la iglesia parroquial de Bagüés es un conjunto de una belleza espectacular para cuya presentación en el Museo Diocesano de Jaca se utilizó una antigua dependencia claustral situada como prolongación de la galería norte, que se adoptó para configurar la reconstrucción fiel de la iglesia original.

Cuando el restaurador catalán Ramón Gudiol llevó a cabo el arranque de las pinturas murales, en julio de 1966, se descubrió en un pequeño hueco tallado en uno de los sillares de la pared del semicilindro absidal, a la altura de la cabeza del Crucificado que la ocultaba, la presencia de una lipsanoteca en madera de boj, lacrada y sellada, envuelta en una larga cinta de lino ${ }^{5}$. En uno de sus lados, una inscripción en letra minúscula visigótica informaba de la dedicación del templo a San Miguel Arcángel, a San Acisclo, a Santa Engracia, a los santos Julián y Basilisa y a San Cristóbal. El mismo texto se repetía en una tira de pergamino de reducido tamaño escrita por ambos lados, conservada dentro ${ }^{6}$. El tipo de letra de las dos inscripciones, minúscula visigótica, corresponde al último cuarto del siglo XI, data que coincide con el modelo arquitectónico de la iglesia; ambas circunstancias permiten situar la cronología de la decoración pictórica mural en una fecha cercana al año 1100 .

La que ha sido calificada como «capilla Sixtina del románico» comprende la decoración de la capilla mayor y de los dos muros de la nave. La decoración del arco triunfal se ha perdido casi por completo. La apertura de dos arcos de medio punto en el muro meridional, con el fin de comunicar la nave añadida con la iglesia primitiva, afectó gravemente al conjunto mural del lado derecho o de la epístola. Y las pinturas, que sin duda había en el muro de los pies como cierre del ciclo narrativo, se perdieron con la construcción de la torre, incorporada con posterioridad.

4 G. M. Borrás Gualis y M. García Guatas (1978), pp. 47-105.

5 La caja mide 3,6 x 6,2 x 5,1 cm. La cubierta, 4 x 33 cm. M. ${ }^{a}$ C. Lacarra Ducay (1993), p. 81.

6 M. García Guatas (1993), pp. 244-245. 
La tradición había impuesto la costumbre de enfrentar en los muros de las naves escenas del Antiguo y Nuevo Testamento. Costumbre que se mantiene tanto en los grandes conjuntos románicos benedictinos como en la iglesia de Sant'Angelo in Formis (Capua) ${ }^{7}$, donde un ciclo del Antiguo Testamento se desarrolla en las naves laterales mientras que las escenas del Nuevo Testamento se encuentran en tres pisos superpuestos de los muros de la nave central.

La iglesia de Bagüés, de una sola nave, ofrece un esquema compositivo diferente, con las escenas del Antiguo Testamento distribuidas en el registro superior, tanto en la nave sur o de la epístola, como en la norte o del evangelio, y las del Nuevo Testamento ampliamente desarrolladas en los tres registros inferiores. Estos últimos se prolongan incluso en el ábside con una representación de la Ascensión del Señor, en la bóveda de horno y de su Pasión y Resurrección, en la pared curvada.

El programa narrativo se inicia en el registro superior del lado meridional o de la epístola junto a la cabecera, y se prolonga hasta alcanzar el muro occidental del templo. Seguidamente hay que trasladarse al muro del lado norte o del evangelio, para continuar la narración en la zona más alta, desde los pies hasta la cabecera. Encima de algunos episodios quedan restos de la banda con inscripciones que aludían a lo representado debajo.

El programa iconográfico comienza con la Creación del mundo, continúa con los pasajes más conocidos del Antiguo Testamento, sigue con el Nuevo Testamento, Nacimiento y Vida pública de Cristo, para terminar en la cabecera con su Pasión, Muerte, Resurrección y gloriosa Ascensión a los cielos. Es decir, incluye desde el Libro del Génesis hasta el de los Hechos de los Apóstoles, como una Biblia ilustrada en imágenes ${ }^{8}$.

7 La pintura mural de la basílica de Sant'Angelo in Formis constituye el conjunto de frescos más completo y mejor conservado de toda la Italia del sur. Según Marcel Durliat (1982): «Las notables variaciones que hay en su estilo no implican necesariamente, como a veces se ha creído, que su composición haya sido llevada a cabo en distintas etapas. Pueden ser el resultado de la participación de artistas de formación y sensibilidad diferentes». Para este mismo autor, la fecha razonable de su realización estaría entre 1072, año en que esta iglesia fue donada al gran monasterio benedictino de Monte Cassino, y la muerte de su abad Didier (1059-1087), es decir, entre 1072 y 1087.

8 G. M. Borrás Gualis y M. García Guatas (1978), pp. 47-105. M. García Guatas (1993), pp. 246-251. M. ${ }^{a}$ C. Lacarra Ducay (1993), pp. 81-84. 
En el lado derecho o de la epístola, en el piso primero, comenzando por arriba, se encuentran las primeras escenas del relato bíblico: Creación de Adán; Dios entrega a Adán el dominio sobre los animales; Dios extrae la costilla del costado derecho de Adán; Creación de Eva; Dios presenta Eva a Adán; Dios muestra a los primeros padres el árbol del bien y del mal; Eva es tentada por la serpiente; Adán es tentado por Eva; Eva y Adán se cubren ante Dios, avergonzados por su culpa. En el lado izquierdo o del evangelio, a la misma altura, se hallan las siguientes escenas: Oraciones de Caín y Abel; Caín da muerte a su hermano Abel; Dios maldice a Caín; Dios habla a Noé y le predice el diluvio; Construcción del arca por Noé con ayuda de sus hijos Sem, Cam y Jafet; Ingreso de Noé y su familia en el arca acompañados de diversas parejas de animales; Fin del diluvio y agradecimiento de Noé, que ofrece sacrificios en el altar.

En el lado derecho o de la epístola, en el piso segundo, donde se encuentran las tres ventanas iguales, se inician las escenas del Nuevo Testamento: Anunciación, la primera ventana, que tiene en su intradós pintada la media figura de Cristo; Visitación de María a su prima Isabel; Nacimiento de Cristo; la segunda ventana, que tiene en su intradós pintada la media figura de la Virgen María; Anuncio a los pastores; Epifanía; la tercera ventana, que tiene pintadas en su intradós las figuras de los Reyes Magos. En el lado izquierdo o del evangelio, en el piso segundo, donde se abre una sola ventana, prosiguen las escenas de la Infancia de Cristo: Huída a Egipto; Herodes ordena la matanza de los niños menores de dos años; una ventana que contiene en su intradós pintada la mano derecha de Dios; Presentación de Jesús en el templo y, finalmente, el Bautismo de Cristo por su primo Juan en el río Jordán.

En el lado derecho o de la epístola, en el piso tercero, se inicia la Vida Pública de Cristo: Tentaciones de Cristo en el desierto; Vocación de los primeros apóstoles: Simón-Pedro y Andrés; Santiago y Juan Evangelista y Bodas en Caná de Galilea. En el lado izquierdo o del evangelio, en el piso tercero, prosigue la Vida de Cristo: Cristo con los apóstoles; Cristo con la Samaritana; Marta y María con Cristo y Resurrección de Lázaro.

En el lado derecho o de la epístola, en el cuarto y último registro, se reconocen, en mal estado de conservación, las escenas de Cristo con Simón-Pedro e Institución de la Iglesia (¿). En el lado izquierdo o del evangelio, en el cuarto y último registro se encuentran: Entrada de Cristo en Jerusalén; una puerta de 


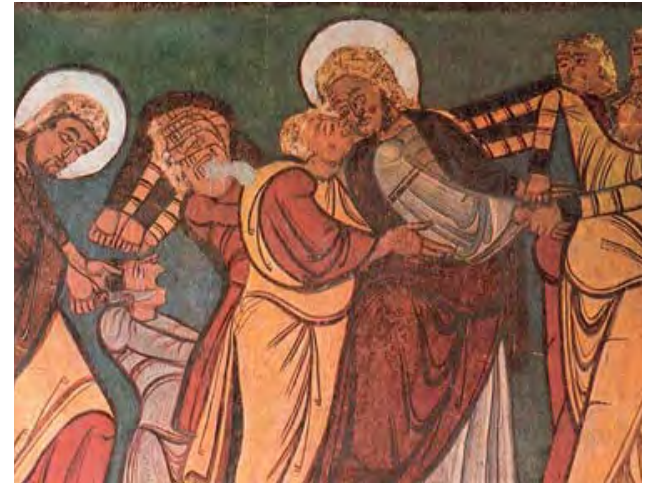

Beso de Judas. Detalle. Lado izquierdo o del evangelio. Pinturas de Bagüés, Museo Diocesano de Jaca (Huesca). acceso al templo, hoy inutilizada, en cuyo tímpano semicircular se encuentra pintado el busto de Cristo bendiciendo acompañado por dos ángeles; Última Cena; Cristo lavando los pies a los apóstoles; Oración en el Huerto y Beso de Judas.

El arco triunfal de ingreso a la capilla mayor se decoraba con pinturas en los lados, hoy casi perdidas, dispuestas en dos registros superpuestos. En el lado izquierdo o del evangelio, en la zona de arriba se encontraba San Juan

Bautista hablando con escribas y saduceos (?), y en el registro inferior, un grupo de soldados con lanzas. En el lado derecho o de la epístola, en la zona de arriba se encontraba San Juan Evangelista con otro personaje (?) y en el piso inferior, la escena de la Resurrección de los muertos y el Encuentro de Cristo resucitado con María Magdalena.

En los muros del ábside la decoración se dispuso en tres pisos o registros: el inferior o zócalo, que simula cortinajes pintados, y dos superiores de tipo narrativo en ritmo ascendente, coincidentes en altura con los que decoran los muros de la nave y el arco triunfal.

En el registro central, bajo la ventana central de iluminación, se representa el tema del Calvario con Cristo en la cruz, de cuatro clavos, flanqueado por los dos ladrones, Dimas y Gestas, escoltados por sus respectivos verdugos. Los soldados romanos Longinos y Stefaton acompañan al crucificado; el primero le perfora el costado derecho con su lanza, el segundo le aproxima a la boca la esponja empapada en vinagre y hiel, sujeta al extremo superior de una caña. La Virgen María y Juan Evangelista, con gesto dolorido, le acompañan situados uno a cada lado de la cruz. Por encima de esta, se encuentran las representaciones del sol y de la luna en figura humana insertadas en círculos.

El tema del Calvario va precedido de la escena de Cristo cargado con la cruz o Vía Crucis, a la izquierda; y se concluye con la escena de las santas mujeres ante el sepulcro vacío, símbolo de la Resurrección de Cristo, a la derecha. Y en el registro 
superior se representa al apostolado, distribuido en dos grupos a los lados de la ventana axial, con la Virgen María en el grupo del lado izquierdo o del evangelio.

La actitud en todos los asistentes es la de mirar hacia lo alto para contemplar a Cristo, que en el centro de la bóveda, asciende a los cielos, tema poco frecuente en la pintura románica europea. Se muestra en pie con los brazos abiertos, inscrito en una mandorla flanqueada por ángeles mancebos.

Una pintura, hoy desaparecida, decoraba el muro occidental de la nave, a los lados y encima de la primitiva puerta principal. Se representaba en ella, según lo acostumbrado, el tema del Juicio Final Universal, con el regreso de Cristo en el último día de la humanidad para juzgar a vivos y muertos, según lo anunciado.

Aunque las modificaciones constructivas efectuadas en la iglesia románica de Bagüés a lo largo de los siglos, como la construcción de la torre campanario y de la segunda nave en el lado derecho, mutilaron algunas escenas, todavía se advierte la firmeza en el trazo, de formas bien silueteadas, que se acercan al procedimiento utilizado en la iluminación de manuscritos, y el uso de colores planos de notable variedad cromática.

Frente a lo que sucede en las pinturas murales de la iglesia inferior del monasterio de San Juan de la Peña, dedicadas al martirio de los santos médicos Cosme y Damián (ca. 1090-1094), cuyos fondos son claros — casi blancos_, en este caso se distingue un fondo de color azul, sobre el que destacan los colores cálidos, ocre, rojo, castaño, junto con el negro y el blanco, sin olvidar el color amarillo para los nimbos de los personajes sagrados?.

El empleo del color azul como fondo en la pintura mural románica europea es algo habitual en el área oriental francesa, de tradición bizantina y origen italiano, como sucede en las pinturas murales de la iglesia de Berzé-la-Ville, priorato de la abadía benedictina de Cluny, en Borgoña, mientras que en las pinturas del occidente de Francia los fondos son habitualmente claros, casi blancos.

Las pinturas murales de Bagüés han sido emparentadas, por razones de estilo, con talleres del centro occidental de Francia, activos en la región del Poitou en torno al ańo 1100, con obras de pintura mural y de miniatura.

En el primer ejemplo, son las pinturas murales de la abadía benedictina de Saint-Savin-sur-Gartempe (Departamento de Vienne), localizadas tanto en su

9 M. ${ }^{a}$ C. Lacarra Ducay (2000), pp. 54-56, figura 22. 


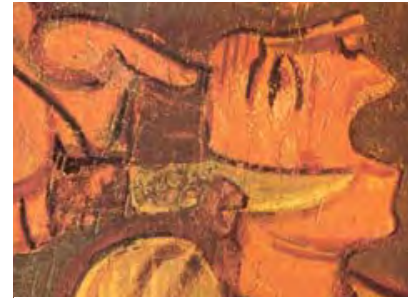

Beso de Judas. Detalle.

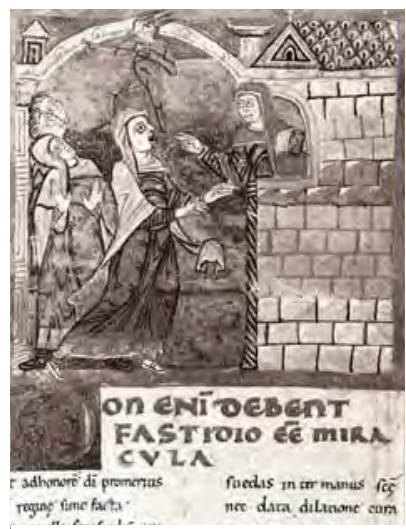

Santa Radegunda libera a la posesa Fraifeda (Vida de Santa Radegunda, Biblioteca Municipal de Poitiers). cripta, con escenas del martirio de los santos Sabino y Cipriano, como en la totalidad de la bóveda de la nave mayor, dedicada al Antiguo Testamento, desde la Creación a la historia de Moisés incluida, datadas cerca del año $1100^{10}$.

$\mathrm{Y}$ en el segundo, son las veintidós miniaturas a gran formato del libro de la Vida de Santa Radegunda (Vita Radegundis), procedente del monasterio de la Santa Cruz de Poitiers, hoy en la Biblioteca Municipal de la ciudad (Poitiers, Ms. Lat. 250), que se relacionan estilísticamente con los frescos de Saint-Savin, con los que comparte el dinamismo narrativo, y manifiestan, de igual modo, su relación artística con Bagüés ${ }^{11}$.

Sobre el único taller que llevó a cabo las ilustraciones del libro de Santa Radegunda, se ha sugerido que pudo estar habituado a trabajar en pintura mural, en una cronología cercana al último cuarto del siglo XI.

Otro ejemplo, un poco posterior, lo constituye el Sacramentario de la catedral de Saint Etienne de Limoges, conservado en la Biblioteca Nacional de París (Ms. Lat. 9438), cuyas ilustraciones de Cristo crucificado (folio 59r) y de la Ascensión (folio 84v)

poseen conexiones iconográficas indiscutibles con las pinturas de la cabecera de Bagüés ${ }^{12}$.

Las alianzas tradicionales de los reyes de Aragón con la casa ducal de Aquitania pueden justificar estas relaciones artísticas y culturales. El futuro rey Pedro I de Aragón (1094-1104), cuando todavía era el heredero del reino, contrajo matrimonio por vez primera en enero de 1086 con Inés de Aquitania, hija de

$10 \mathrm{~J}$. Wettstein (1978), pp. 4-24, figuras 1-12.

$11 \mathrm{~J}$. Wettstein (1978), pp. 27-31 y pp. 97-108, figs. 1-24.

12 Se trata de una compilación de plegarias para el oficiante de la misa, realizada por encargo del cabildo de la catedral de Saint-Étienne. Se adorna con once ilustraciones policromadas de gran belleza, obra de un solo taller, que se han datado hacia el año 1100. Véase: J. Wettstein (1978), p. 107. 
Gui-Geoffroi —también llamado Guillermo viII-, conde de Poitou y duque de Aquitania (1058-1086), y de Audearde o Aubrade, hija de Roberto I, duque de Borgoña (1033-1076).

Este enlace establecía lazos estrechos con dos de las más importantes estirpes de príncipes de la época, con la gran abadía de Cluny y con el pontificado romano, y lo colocaba «en primera fila de los príncipes europeos». De esta unión nacería un solo hijo, Pedro, que no sobrevivió a su padre.

Un segundo matrimonio del monarca, en agosto del ańo 1097, con una tal Berta, dama de enigmática procedencia e ilustre linaje, a la que se ha supuesto un origen italiano por parte de padre, y que su madre fuera prima hermana de la primera esposa del rey, tampoco le daría el ansiado heredero; pero no hizo sino reforzar la relación con Aquitania, al pertenecer a la misma rama familiar que la anterior ${ }^{13}$.

Sin renunciar a estas influencias francesas del Poitou, conviene señalar, además, la variedad y riqueza de modelos culturales que se desarrollaron en el reino de Aragón durante la segunda mitad del siglo xi y recordar que, hasta la reconquista de la ciudad de Huesca por el rey Pedro I, en 1096, fue Jaca el lugar elegido por su padre, el rey Sancho Ramírez (1064-1094), para situar la capitalidad del pequeño reino de Aragón en el territorio regado por el río de su nombre que había quedado desglosado de la monarquía pamplonesa a la muerte del rey Sancho Garcés inI el Mayor, en el año

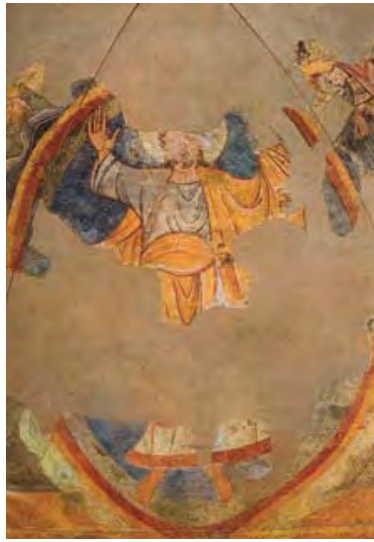

Ascensión. Detalle del ábside de Bagüés. Museo Diocesano de Jaca (Huesca).

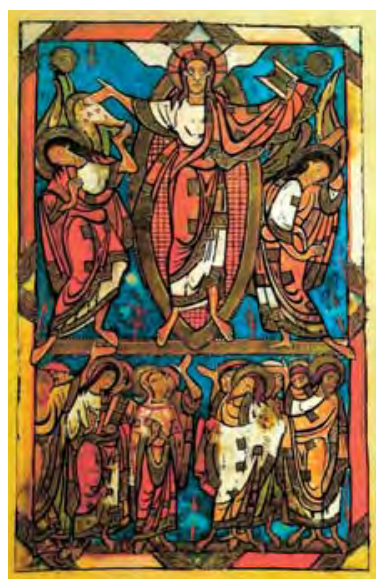

Ascensión (Sacramentario de San Esteban de Limoges, Biblioteca Nacional de Francia, París). 1035.

La situación estratégicamente favorable de la ciudad de Jaca, en la vertiente sur de los Pirineos, en una ladera que domina una amplia llanura donde se bifurca- 
ban dos rutas importantes - la occidental de enlace con los reinos de Navarra y Castilla, y la septentrional, antigua vía romana de Bearn a Zaragoza—, justificaba la elección real en donde hasta entonces había sido una aldea poblada por pastores y modestos campesinos en la que ya existía un monasterio dedicado a San Pedro apóstol.

La política europeísta desarrollada por Sancho Ramírez, manifestada abiertamente en sus actuaciones personales con sus estrechas relaciones con la Santa Sede y con la abadía de San Pedro de Cluny, fructificó en la nueva orientación que supo dar a su reino. Así, no solo concedió el Fuero de población a Jaca, en 1077, con el que se convirtió legalmente en ciudad, sino que introdujo la liturgia romana en sustitución de la liturgia hispánica o mozárabe, y estableció la reforma gregoriana y la regla benedictino-cluniacense en los centros monásticos de su territorio. Y a su iniciativa se debe el inicio de su catedral, dedicada a San Pedro, monumento singular de estilo románico dentro del contexto europeo de su tiempo.

La creación en Jaca de un núcleo de población extranjera, especialmente francesa, el llamado Burnau (Burgnou) o Burgo Nuevo de la ciudad, constituido por mercaderes y artesanos, contribuyó a darle un aire más cosmopolita, acrecentando su prosperidad económica.

La unión de los reinos de Aragón y de Navarra —a la muerte en Peñalén (Merindad de Olite) de Sancho Garcés Iv de Navarra, en 1076 — en la figura del monarca aragonés Sancho Ramírez, que se mantendría hasta el fallecimiento de Alfonso I el Batallador en 1134, tuvo que favorecer la venida de peregrinos por las facilidades otorgadas por la realeza a quienes atravesaban el reino por Jaca y

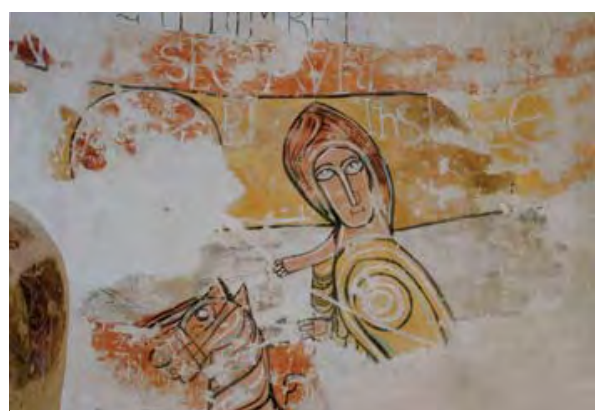

Hombre montado a caballo. San Esteban de Almazorre (Huesca). Cabecera, lado derecho o de la epístola. por Pamplona, con dirección a Santiago.

Y a poca distancia de Jaca, en dirección a Navarra, se encontraba el ilustre monasterio benedictino de San Juan de la Peña, protegido por la casa real de Aragón, del que dependía en su calidad de priorato la iglesia de Bagüés. Y, en este monasterio, existía un destacado taller de miniaturistas y pintores activos durante los años en que se decoraba la iglesia de los santos Julián y Basilisa. 
2.

Las pinturas murales de la iglesia de San Esteban de Almazorre, recientemente descubiertas, proporcionan datos nuevos sobre la pintura románica en el Alto Aragón ${ }^{14}$. Estas pinturas, perfectamente documentadas, contribuyen a identificar la existencia de un taller itinerante al que se pueden atribuir otras obras de pintura mural y sobre tabla por su similitud estilística ${ }^{15}$.

Almazorre es una pequeña localidad de la comarca de Sobrarbe, situada al nordeste de la provincia de Huesca, a cuya diócesis pertenece. $\mathrm{Su}$ iglesia parroquial se encuentra ubicada en la ladera de una colina, en un promontorio rocoso, a cierta altura de la población que queda abajo.

Es un edificio de origen románico, realizado en mampostería irregular, que conserva la cabecera y la parte baja de la torre de su época fundacional, a principios del siglo XII, durante el reinado de Alfonso I el Batallador (1104-1134). El resto es el resultado de ańadidos y reformas, efectuados dentro y fuera del edificio en diferentes épocas, que adulteraron su carácter primitivo.

Se trata de una iglesia de pequeñas proporciones, de una sola nave, con acceso por el lado meridional, o muro de la epístola, con arco de medio punto adovelado protegido por un pórti-

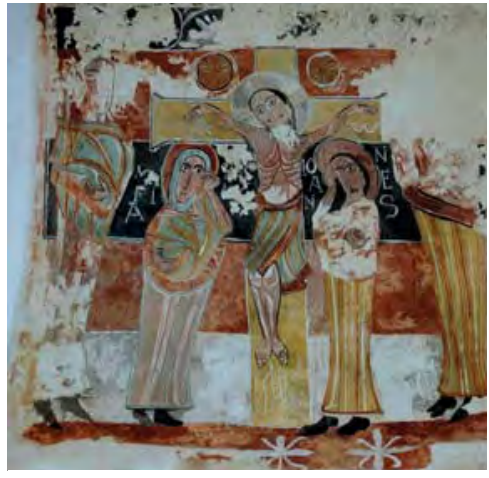

Calvario. Iglesia de San Esteban de Almazorre (Huesca).

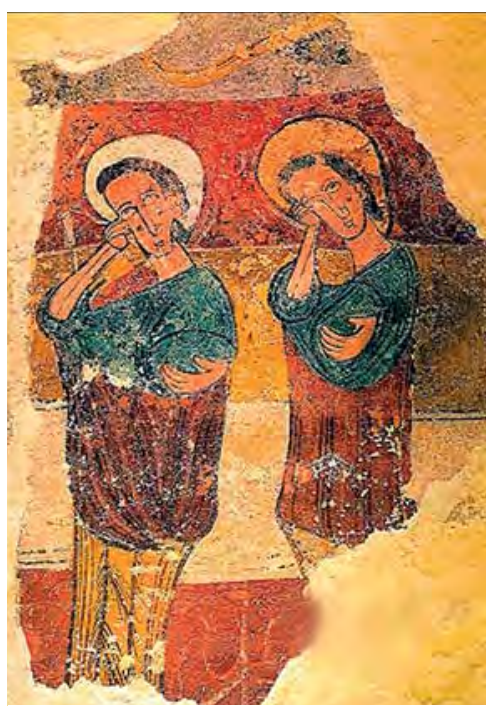

Dos apóstoles. Iglesia de Santa Eulalia de Mérida, Susín (Huesca). Museo Diocesano de Huesca.

14En el año 2006, técnicos del Servicio de Conservación y Restauración de la Dirección General de Patrimonio Cultural del Gobierno de Aragón junto al párroco don José María Cabrero descubrieron restos de pintura mural románica en la cabecera del templo, oculta bajo una capa de color azul fuerte incorporada en época moderna. Las tareas de restauración se iniciaron seguidamente para finalizarse en el otoño del año 2009.

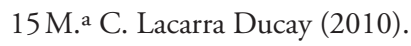


co. Su cabecera, de planta semicircular precedida de tramo, se cubre con bóveda de cuarto de esfera y con bóveda de medio cañón el tramo que la precede. La nave recibe bóveda de medio cañón apuntada, articulada en tres tramos por dos arcos fajones que apean en ménsulas adosadas a cierta altura del muro. Su iluminación se efectuaba a través de un vano de pequeño tamaño, abierto en el muro del ábside con arco de medio punto abocinado.

En el tramo anterior a la cabecera se adosan sendas capillas laterales de planta rectangular y testero recto, cubiertas con bóveda de medio cañón, que se abren a la nave con arco de medio punto, a modo de falso transepto. Son incorporaciones ańadidas al edificio románico en época moderna. La torre campanario se encuentra en el lado meridional, cercana al presbiterio. Tiene planta cuadrada y presenta dos pisos separados por una imposta con el cuerpo superior para campanas culminado por un chapitel octogonal. Se accede a ella desde el exterior, y la fecha grabada en el lado meridional, «1867», puede aludir a una posible reparación o reforma.

Al terminar la edificación de la iglesia se decoró su interior con pinturas murales al temple, en estilo románico, que hay que datar entre los años 1130 y 1131 , cronología que se apoya en el documento de consagración hallado bajo la mesa de altar, en el presbiterio. Aunque lo que haya llegado hasta hoy de esta decoración sea escaso, es grande su importancia a nivel histórico-artístico ya que no son muchas las pinturas que se conservan en el Alto Aragón de las que se tengan datos fidedignos de su cronología.

Debajo de la mesa del altar apareció enterrado entre piedras un texto escrito en letra carolina, con tinta negra sobre pergamino, que incluye la fórmula de consagración, la fecha —el día 6 de enero del año 1131-y el nombre del obispo ejerciente — don Arnaldo Dodón de Huesca-Jaca (1130-1134). Acompañaban al documento sendas reliquias de San Juan Bautista y de San Andrés apóstol, identificadas por el texto con su nombre escrito en el pergamino que las acompañaba para protegerlas.

Esta información documental, de extraordinario valor histórico, ayuda a datar la construcción del templo en la primera mitad del siglo XII y proporciona, además, el nombre de su primitiva advocación —San Esteban protomártir-, que, en fecha posterior al siglo XVI y sin que se pueda aventurar la causa, se sustituyó por la de San Agustín, obispo de Hipona, su advocación actual. 
Debemos a don Antonio Durán Gudiol un importante estudio monográfico dedicado a los obispos de Huesca y Roda en la primera mitad del siglo XII, en el que trata la controvertida personalidad de don Arnaldo Dodón, obispo de Huesca y Jaca entre 1130 y 1134 y, anteriormente, canónigo de Roda de Isábena ${ }^{16}$.

Su corto pontificado abarca desde marzo de 1130 hasta su muerte, acaecida el 19 de julio de 1134. Su fallecimiento habría tenido lugar el mismo día que el del obispo don Pedro Guillermo, de Roda-Barbastro (1129-1134), como consecuencia de la derrota de Fraga (Huesca) sufrida por el Batallador frente a los musulmanes, a quién habrían acompañado en la campaña.

Y los años de mandato del obispo Arnaldo Dodón coinciden, como nos recuerda el Padre Ramón de Huesca ${ }^{17}$, con los últimos del reinado de Alfonso I (1104-1134), quién terminó sus días en septiembre de ese mismo año ${ }^{18}$. Con la desaparición del rey Batallador, se consumó la separación de los reinos de Aragón y Navarra, siendo entronizado en el primero Ramiro ir el Monje, hermano de Alfonso I; y en el segundo, García Ramírez, conocido como «el Restaurador».

La pintura original cubría la totalidad de la cabecera de la iglesia, bóveda e intradós del arco triunfal de ingreso a la capilla mayor. Puede que continuase la decoración a lo largo de los muros de la nave, aunque de ello no quedan restos suficientes que autoricen una conclusión definitiva.

En la bóveda de cuarto de esfera que cubre la capilla mayor, se representaba un Cristo en Majestad entronizado, perfectamente identificable, insertado en una mandorla flanqueada por la representación simbólica de los cuatro evangelistas: Mateo, el hombre alado, Marcos, el león, Lucas, el toro, y Juan, el águila. Se trata de una iconografía habitual en época románica para ocupar la cuenca del ábside que tiene como fuente literaria el Apocalipsis de San Juan (4-6-8).

\footnotetext{
16 Con el título de «La Santa Sede y los obispos de Huesca y Roda en la primera mitad del siglo XII», fue publicado por primera vez en la revista Antólogica Annua, n. ${ }^{\circ} 13$ (Roma, 1965, pp. 35-134) por el Instituto Español de Historia Eclesiástica. En 1994, este trabajo fue publicado de nuevo por el Departamento de Educación y Cultura del Gobierno de Aragón, en un solo volumen, Los obispos de Huesca durante los siglos XII $y$ XIII, junto con otros tres estudios del mismo autor.

17 P. Huesca (1797), p. 179.

18 Alfonso I, rey de Aragón y de Navarra, sobrevivió a la batalla de Fraga y falleció en el lugar de Poleñino (Sariñena, Huesca), el 7 de septiembre de 1134. Su lugar de enterramiento fue el castillo-abadía de Montearagón, a la vista de la ciudad de Huesca. José M. ${ }^{a}$ Lacarra (1978), pp. 130-137.
} 
La imagen de la divinidad se muestra en posición frontal y entronizada, flanqueada por el Alfa y la Omega. Bendice con la mano derecha y sujeta el libro de los evangelios con la izquierda. Estaba ataviada con túnica y manto, de los que se reconocen algunos pliegues, paralelos y quebrados, en la parte baja del cuerpo. Se encuentra dentro de una mandorla o silueta de forma almendrada, que no limita su figura, tal y como se advierte en la mano derecha y en los pies descalzos situados encima.

Quedan fragmentos de su rostro y del nimbo crucífero que enmarca su cabeza. Es el tipo de Cristo encarnado que persiste después de su misión terrestre, en el que los signos de la Pasión perduran imborrables, como vemos en los pies, que conservan las heridas producidas por los clavos de la crucifixión. El trono es un escabel con almohadón encima. Las imágenes de los símbolos de los evangelistas, que flanquean la mandorla, se distinguen fragmentariamente. Son medias figuras nimbadas y con alas, cuyas cabezas se dirigen hacia la Divinidad que preside la composición.

En el medio cilindro del ábside se abre una ventana de arco de medio punto y disposición abocinada para dotar de luz al presbiterio, vano que sirve de centro de la composición pictórica que la flanquea.

La zona mejor conservada corresponde al lado derecho o de la epístola y representa a un hombre montado a caballo que se dirige hacia la ventana. De rostro alargado, nariz recta, boca pequeña y grandes ojos abiertos que miran de frente al espectador, recuerda a otras representaciones pintadas en época románica de origen pirenaico. Se cubre con un original tocado a modo de turbante, terminado en punta, y se protege el cuerpo con un escudo que cubre su brazo izquierdo. La cabeza de su montura, de color castańo, reproduce fielmente la de un equino en posición de avanzar hacia la ventana.

En el lado izquierdo, o del evangelio, quedan restos de otro posible jinete, del que se distingue la cabeza del caballo y parte de sus extremidades, en actitud de cabalgar hacia el centro del ábside. Y, a cada lado de la ventana, se pintaron sendos crismones, que pueden interpretarse como signos de consagración, de los que está mejor conservado el del lado derecho del observador.

Tal vez se podría identificar esta escena como la representación del enfrentamiento entre las fuerzas del bien y del mal, entre la fe cristiana y el Islam, tema idóneo para su desarrollo en una tierra de frontera y en un ambiente imbuido 
por el espíritu de cruzada. El caballero cristiano sería aquel situado en el lado izquierdo o del evangelio, apenas visible en la actualidad, y el enemigo de la fe de Jesucristo sería el soldado ataviado a la morisca, ubicado en el lado derecho o de la epístola.

En la parte baja del muro, a manera de zócalo, hay una decoración pintada que reproduce unos cortinajes o paños bordados, algo frecuente en esa zona del ábside en la pintura mural románica.

La decoración prosigue en el arco triunfal de acceso al presbiterio con diversas composiciones de carácter narrativo dispuestas en el intradós del arco. Son de difícil identificación debido a su grave estado de deterioro.

Coincidiendo con el lado izquierdo o del evangelio, se representa un Calvario, con el Crucificado flanqueado por la Virgen María y San Juan Evangelista, uno a cada lado de la cruz, sobre un fondo de bandas horizontales de diversos colores. Se distingue nítidamente a Cristo muerto con el paño de pureza atado a las caderas, nimbo crucífero y brazos y pies clavados con cuatro clavos al madero, según la iconografía románica tradicional. María y Juan, acompañados por sus nombres — «Maria», «Ioannes»—, en posición erguida y con gesto de dolor, se cubren con largos ropajes hasta los pies. Lucen nimbos de santidad y sus rostros repiten las facciones ya vistas en los personajes pintados en la cabecera. En los extremos, hay pintados dos hombres, a mayor escala que el resto, parcialmente borrados. Podrían ser los profetas David y Juan el Bautista, pareja antitética que confirma el simbolismo de la composición, o el lancero Longinos y el porta-esponja Stéfaton, que mantienen la ordenación simétrica del tema simbólico, para enriquecerlo. Por encima del árbol de la cruz se reconocen sendos círculos radiales, identificables con el sol y la luna.

En el lado derecho o de la epístola, se aprecia lo que pudiera ser el grupo de una Epifanía, al distinguirse dos personajes que avanzan de derecha a izquierda del observador, cubiertos con originales tocados terminados en punta, quienes parecen llevar objetos en sus manos.

Otras composiciones, casi perdidas y de difícil identificación dado su mal estado, se distribuyen en el intradós del arco.

Además interesa destacar la abundancia de inscripciones existentes en la cuenca del ábside, en la zona de separación entre la bóveda y el muro, realizadas en letras mayúsculas latinas con abreviaturas. Son de diferentes épocas y de manos 
distintas, como se advierte por su policromía y grafía diferenciada, de difícil lectura. En el lado izquierdo del muro, es posible leer: «(En)carnac(io(n)», y en lado derecho hay nuevos trazos incompletos.

Tanto el paso del tiempo como la humedad, a lo que se sumaron repintes posteriores, adulteraron su policromía original. Hoy, con ocasión de las transformaciones efectudas en el edificio, son los tonos tostados y ocres, el almagre, el blanco y el negro, los colores que predominan en una gama de evidente pobreza cromática, al haberse perdido los colores fríos, como el azul y el verde.

El análisis estilístico de las pinturas de Almazorre las identifica como románicas, de carácter popular, dentro de las tendencias del Pirineo central de la primera mitad del siglo XII. Y, al mismo taller, hay que atribuir dos obras de pintura mural y sobre tabla procedentes de la provincia de Huesca, de las que hasta ahora no se precisaba con exactitud su cronología.

\section{3.}

De la iglesia parroquial de Santa Eulalia de Mérida en la aldea de Susín, localidad de la provincia de Huesca situada en la margen izquierda del río Gállego, en la diócesis de Jaca, proceden dos fragmentos irregulares de pintura mural que decoraban el centro de su cabecera, similares a las pinturas de Almazorre. Eran parte de una decoración mural desaparecida por las reformas que afectaron al edificio en el siglo XVIII, que fueron descubiertas de manera casual y arrancadas de la pared en 1966, para su posterior exposición en el Museo Diocesano de $\mathrm{Jaca}^{19}$.

El fragmento de mayor tamaño corresponde a dos figuras apostólicas imberbes, en posición erguida y expresión doliente, que lucen nimbos de santidad. El fragmento menor representa parte de la mitad izquierda del cuerpo de otra figura en pie que tiene el brazo izquierdo levantado, con restos de una inscripción ilegible sobre unos signos o trazos igualmente incompletos. Y, en los dos casos, las figuras destacan sobre un fondo de bandas horizontales de distintos colores, como en la cabecera de Almazorre. 
Las pinturas murales de Susín fueron relacionadas por don José Gudiol ${ }^{20}$, por razones formales, con el conocido como «Maestro del Juicio Final», el tercero de los tres pintores que trabajaron en la iglesia de Santa María de Tahull, situada en el valle de Bohí (Lérida), que fue consagrada el 11 de diciembre de 1123. Habría colaborado simultáneamente con los demás maestros, autores de la pintura de las capillas orientales, en la pintura de las naves y del muro occidental de la iglesia. Esta atribución fue rechazada luego por algunos historiadores aragoneses, que se las otorgaron a un pintor arcaizante, de carácter popular y origen autóctono, dentro de la primera mitad del siglo XII ${ }^{21}$.

Años más tarde, un nuevo estudioso del arte medieval aragonés, catalogaba los fragmentos de pintura mural de la iglesia de Susín como de los años centrales del siglo XI, durante el reinado de Ramiro I de Aragón (1035-10964), cronología que proponía también para la iglesia que las cobijaba ${ }^{22}$. Esta temprana datación de las pinturas de Susín se contradice abiertamente con los datos históricos que se poseen de la consagración de la iglesia de Almazorre, los cuales obligan a datarlas en los años finales del reinado de Alfonso i el Batallador (1104-1134).

Recientemente, el profesor Castiñeiras ha recuperado la tesis propuesta por Gudiol Ricart para las pinturas de Susín, que hace extensible también a Almazorre, confirmando la vinculación ribagorzana de estos murales aragoneses en relación con el tercer maestro de Santa María de Tahull23.

\section{4.}

En el Museo Diocesano de Barbastro se custodia un fragmento de pintura sobre tabla que fue descubierto de manera casual en el año 1974 en la iglesia parroquial de San Vicente de Vió, localidad de la comarca de Sobrarbe situada al nor-

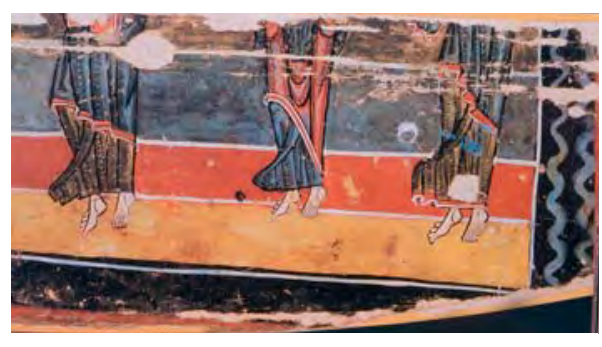

Figuras de santos, restos de un Calvario (?). Procede de San Vicente de Vió (Huesca). Museo Diocesano de Barbastro (Huesca).

20 J. Gudiol Ricart (1971), pp. 8-9, figs. 6 y 7.

21 G. M. Borrás Gualis y M. García Guatas (1976), pp. 145-155.

22 F. Galtier Martí (2006), pp. 220-222.

23 M. Castiñeiras (2010), pp. 57-61. 
deste de la provincia de Huesca ${ }^{24}$. Se encontraba clavado en la parte posterior de una de las dos vigas paralelas que, empotradas en la parte superior del ábside, habían servido para sostener un retablo del siglo xvi que fue destruido durante la guerra de 1936. Se ha supuesto que pudo constituir parte de un baldaquino o de un frontal de altar, sin poder aclarar este aspecto debido a su mal estado de conservación.

Respecto a su iconografía, dada la disposición horizontal del fragmento que mutila la parte superior de la composición, se puede aventurar que se trataba de un Calvario, por el madero puntiagudo dispuesto de manera vertical pintado en el extremo izquierdo, y por las cuatro figuras humanas en posición erguida, tres de ellas descalzas y con túnica, que ocupan la zona restante de la tabla.

Las cuatro figuras se representan sobre un fondo de bandas horizontales de distintos colores, similares a las que se encuentran en las pinturas murales de Almazorre y Susín.Y, también, se repiten los convencionalismos en el dibujo y en la representación de los pliegues de los vestidos de los personajes representados, según se observa en los ejemplos mencionados.

Este pequeño e irregular fragmento de tabla pintada ya había sido atribuido por razones de estilo al taller del llamado por el profesor García Guatas, en 1993, «Maestro del Juicio Final de la iglesia de Santa María de Tahull», quien asimismo recordaba que las dos iglesias del valle de Bohí — San Clemente y Santa María de Tahull- fueron consagradas por San Ramón, obispo de Roda-Barbastro (1104-1126), en diciembre de 1123. Este santo prelado, de familia noble y origen francés, había sido prior de la comunidad de canónigos regulares de la colegiata San Saturnino de Toulouse cuando fue nombrado, por unanimidad de los canónigos de Roda de Isábena, obispo de la dúplice sede episcopal con el beneplácito del rey Pedro i de Aragón, que fallecería al poco tiempo ${ }^{25}$.

Si se tiene en cuenta la proximidad geográfica que enlaza las localidades oscenses de Almazorre y de Vió y sus vinculaciones con la sede de Roda de Isábena, no hay duda de que se trata de una nueva realización del mismo taller activo en tierras pirenaicas en el primer tercio del siglo XII, coincidiendo con el reinado de Alfonso i el Batallador. 
5.

Con el nombre de Ruesta se identifica una antigua villa situada al norte de la provincia de Zaragoza, en la comarca de las Cinco Villas, perteneciente a la diócesis de Huesca-Jaca, que quedó despoblada hace medio siglo y fue anexionada entonces al cercano lugar de Urries.

Fue una importante plaza fuerte durante la Edad Media aragonesa por su estratégica situación fronteriza con Navarra, en las proximidades de Sangüesa, como se confirma por los restos de un importante castillo fortaleza que era propiedad de judíos a principios del siglo xIv. Junto con las localidades de Salvatierra de Escá, Tiermas y Sos del Rey Católico, eran las plazas fundamentales de defensa del norte del reino de Aragón durante la época medieval.

La villa de Ruesta era paso obligado de los peregrinos que iban a Compostela por la orilla izquierda del río Aragón, en donde había un puente de piedra para cruzar y llegar a la villa de Tiermas, situada enfrente, desde donde se unía con el camino de la margen derecha del río que venía por la canal de Berdún, que era más llano y, probablemente, más concurrido $^{26}$.

Su iglesia parroquial estaba dedicada

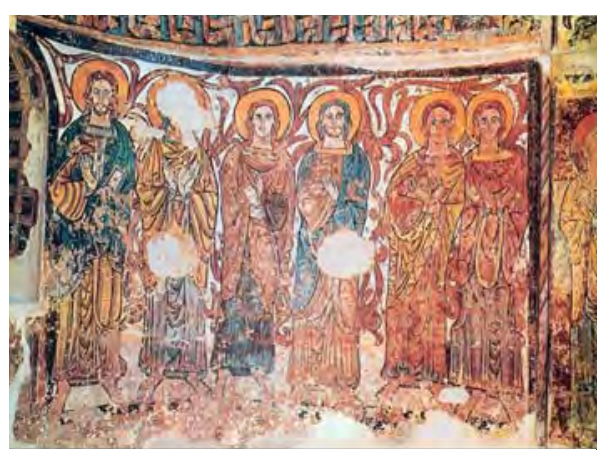

Apostolado. Iglesia de San Juan Bautista de Ruesta (Zaragoza). Museo Diocesano de Jaca. a Santa María en su Asunción y, en los alrededores, había tres ermitas consagradas a San Juan Bautista, a Santiago Apóstol y a San Sebastián.

En el año 1054, con motivo de unas paces que se firmaron entre los reyes de Navarra y Aragón, el monarca navarro Sancho el de Peñalén cedió a Ramiro I de Aragón la localidad de Ruesta. Y, en 1087, la iglesia de Santiago con su alberguería fue donada por el rey Sancho Ramírez a la abadía francesa de La Sauve-Majeure, cercana a Burdeos.

26G. M., Borrás Gualis, J. Fco. Esteban Lorente y M. García Guatas (1977), pp. 209-216. 
La ermita de San Juan Bautista, situada a las afueras de la población, a poca distancia de la de Santiago, era un edificio de pequeñas dimensiones, de una sola nave, que tenía cubierta de madera y cabecera semicircular con bóveda de cuarto de esfera, según el estilo románico de carácter rural de la zona. El acceso tenía lugar por una sencilla puerta de arco de medio punto situada en el centro del lado meridional. La pobreza de su construcción, en mampostería irregular, se compensaba con la pintura mural al fresco que recibió su cabecera; según parece, su única decoración. En la actualidad se encuentra abandonada y en estado ruinoso.

Las pinturas murales de San Juan Bautista de Ruesta fueron descubiertas por don Jesús Aurizanea, párroco de Urriés, en el verano del año 1963. Arrancadas de los muros por el restaurador catalán Ramón Gudiol, fueron llevadas a Barcelona para su traslado a un nuevo soporte, restauración y limpieza. Terminado el trabajo en junio del ańo siguiente, en julio se expusieron por vez primera durante unos días en el Palacio de la Virreina de la ciudad condal para darlas a conocer públicamente antes de su instalación definitiva en el recién fundado Museo Diocesano de $\mathrm{Jaca}^{27}$.

Coincidiendo con dicha exposición, fueron objeto de una primera catalogación por el profesor Alcolea, quién destacaba su valor histórico-artístico dentro del románico hispano ${ }^{28}$. Con ellas se iniciaba un nuevo capítulo en la historia de la pintura románica española que sucesivos descubrimientos de pinturas murales pertenecientes a la diócesis de Jaca, efectuados pocos años después, no harían sino confirmar. En Aragón, frente a lo que se pensaba, había habido, durante los siglos XI y XII, una escuela de pintura mural importante capaz de rivalizar con otras escuelas localizadas en Cataluńa, León y Castilla la Vieja.

La decoración pictórica de la iglesia de San Juan Bautista de Ruesta ocupaba el cascarón del ábside cubierto con bóveda de cuarto de esfera, el muro semicilíndrico que lo configura, interrumpido por una ventana central de iluminación, y el tramo previo de acceso al presbiterio, con bóveda de medio cañón.

En la bóveda se representa la visión de la Maiestas Domini y el Tetramorfós según se nos describe en el Apocalipsis de San Juan (4, 2-7). Cristo figura sentado en un trono en posición frontal, con la mano derecha levantada en actitud de 
bendecir y con la izquierda sobre el libro de los Evangelios apoyada en la rodilla del mismo lado. Viste túnica de color azul y se envuelve en un manto de color amarillo, abierto por delante y recogido a la altura del vientre para caer hasta los tobillos en abundantes pliegues en forma de cascada que dejan ver sus pies descalzos. Luce nimbo crucífero y su rostro alargado, enmarcado por cabellera oscura y barba del mismo color, es apacible y tranquilo.

A los lados de Cristo se disponen colgadas las siete lámparas del texto apocalíptico que reproducen modelos populares en barro cocido. La mandorla que rodea su figura no la cierra sino que la enmarca y enaltece como un nimbo con un contorno a base de cintas entrelazadas bordeadas de nubes blancas. Así, sus pies superan ampliamente el límite inferior de esta y lo mismo sucede con los cuatro medallones que la flanquean ocupados por ángeles mancebos en actitud de andar alejándose del centro pero con su cabeza vuelta hacia Cristo, portadores en sus manos de los símbolos de los cuatro evangelistas o Tetramorfós: Mateo, Juan, Marcos y Lucas.

Completan la decoración de la bóveda sendos serafines con seis pares de alas cubiertas de ojos en su misión de acompañar al trono de Dios, según la profecía de Isaías (6, 1-4). Una ancha greca separa el cascarón del semicilindro que le sirve de apoyo, solo interrumpida en los extremos por los pies descalzos de los dos serafines situados encima.

El muro absidal queda dividido en dos partes iguales por la ventana central abocinada en arco de medio punto que daba luz al altar. Bajo la ventana se halla la representación del anagrama de Cristo, de notable tamaño.

Para la decoración de los muros situados a cada lado de la ventana se dispuso una iconografía poco común en esta zona de la cabecera ya que rompe el criterio de simetría. A la izquierda del observador, que se corresponde con el lado del evangelio, había pintado un Calvario - con Cristo en la cruz entre la Virgen y Juan Evangelista - del que quedan restos, y a la derecha, que pertenece al lado de la epístola, se pintaron seis apóstoles en representación de los doce, que simbolizan la difusión universal del mensaje de Cristo como redentor del género humano.

El grupo del Calvario, hoy casi borrado, sigue la tradición de los talleres de miniatura románica de la segunda mitad del siglo xiI, con el crucificado de cuatro clavos, sus acompañantes erguidos flanqueando la cruz y, por encima del 
madero, las alegorías de la luna y el sol, encerradas en círculos, simétricamente colocadas.

Los apóstoles, en posición erguida, separados por decoración vegetal estilizada, se muestran descalzos y nimbados, y llevan alternativamente libros cerrados en sus manos. Los dos primeros se identifican con los apóstoles Simón y Judas Tadeo por los nombres situados encima; el siguiente, de rasgos juveniles y carente de barba, con Juan apóstol y evangelista, mientras que los tres que le siguen están desprovistos de cualquier tipo de inscripción que permita su identificación. El fondo de esta zona del ábside es de color blanco, en contraste con la bóveda, que tiene el fondo de color azul.

El programa se completaba con la pintura con que se decoraba el arco triunfal de acceso a la capilla, donde elementos vegetales estilizados en el intradós y representaciones figurativas en el exterior mostraban la atención concedida al mensaje simbólico de la obra. Así, en la enjuta del lado derecho o de la epístola, la única que se conserva, se encuentra un elegante pavo real como alusión a la inmortalidad del alma, que se vería acompañado originariamente de otro similar en el lado contrario.

En la zona interior del arco, en el lado derecho se encuentra la imagen del apóstol San Pedro, identificado por su iconografía tradicional, que formaría pareja con la imagen del apóstol San Pablo situada en el lado izquierdo, hoy desaparecida $^{29}$.

Si en estas decoraciones el desconocido pintor, identificado por el profesor Alcolea como "Maestro de Ruesta», manifestaba ya un incipiente naturalismo en la sonrisa que aflora en los labios de los personajes sagrados, mayor severidad trasmite la cabeza de otro Pantocrátor descubierto en el muro del ábside al arrancar las pinturas de su soporte original, coincidiendo con la cabeza de la Maiestas Domini. Pintura de facciones más acentuadas que se expone próxima al lugar donde se encuentra la cabecera de la iglesia de Ruesta, en el mismo museo $^{30}$.

Creemos, como el doctor Alcolea, que fue un mismo pintor el autor de ambas decoraciones y que, por motivos no conocidos, cambio de gusto o de programa 
en el comitente o ensayo previo de la composición, se decidió pintar encima otra versión más humanizada. En opinión de Spencer Cook y Gudio Ricart, «parece ser un ensayo técnico o una prueba de maestría para convencer al patrocinador de la obra ${ }^{31}$.

Las características formales del pintor de Ruesta, de potente personalidad artística, como lo confirman la libertad en el dibujo y su variada policromía, corresponden a un maestro pirenaico de estilo románico avanzado que cabría fechar en los años finales del siglo XII.

\section{6.}

Y a este mismo taller hay que atribuir, por su similitud estilística, los retratos de Ramiro I y de sus dos hijos —el futuro heredero don Sancho (Sancho Ramírez) y su hijo natural, el obispo Sancho de Aragón—, realizados a dos tintas (roja y negra),

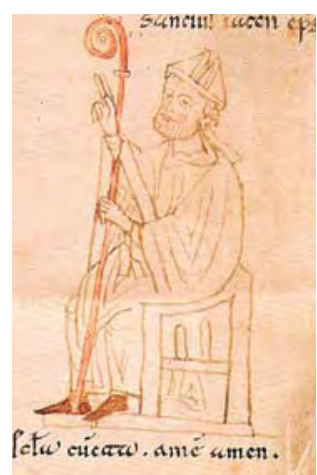

El obispo don Sancho de Aragón (1058-1074?). Archivo de la catedral de Jaca. que ilustran un documento sobre pergamino de gran interés histórico-artístico que pertenece al archivo de la catedral de $\mathrm{Jaca}^{32}$.

Se trata de una falsificación que contiene la donación de trece iglesias a la catedral de San Pedro de Jaca realizada por Ramiro I de Aragón (1035-1064), en abril de 1063, en presencia de su hijo y heredero don Sancho (el futuro rey Sancho Ramírez) y de su hijo natural el obispo Sancho de Aragón (1058-1074?), que habría sido realizada para defenderse de las apetencias del vecino monasterio de San Juan de la Peña ${ }^{33}$.

31 W. W. S. Cook, J. Gudiol Ricart (1980, 2a ed.), pp. 80-81, fig. 83.

32 A. I. Lapeńa Paul (1993), pp. 292-293.

33 A. Durán Gudiol (1962), p. 105. 
Escrita en letra minúscula visigótica muy influida por la carolina, la copia tuvo que hacerse en el entorno de la Seo de Jaca en fecha próxima al año 1200, según ha demostrado el doctor Antonio Ubieto ${ }^{34}$. Y de esa cronología, aproximadamente, serían las ilustraciones que la decoran, en perfecta sintonía con las pinturas murales de San Juan Bautista de Ruesta y con la decoración del frontal de Santa María de Iguácel.

\section{7.}

En el valle de la Garcipollera («o de las cebollas»), perpendicular al valle del río Aragón, en pleno Pirineo de Huesca, se encuentra la iglesia de Santa María de Iguácel, cuyo propietario, el conde Sancho Galíndez, uno de los hombres más influyentes en la corte de los reyes Ramiro I y Sancho Ramírez, de quién había sido su preceptor, terminaba el año 1072, siendo dotada por el rey Sancho Ramírez (1064-1094) con el señorío de la vecina villa de Larrosa ${ }^{35}$.

En el año 1080, el conde Sancho Galíndez y su esposa Urraca donaban, en su último testamento, el santuario de Iguácel y su patrimonio al monasterio benedictino de San Juan de la Peña, cuyos monjes lo convirtieron en priorato dependiente de esta abadía benedictina, lo que se mantuvo hasta los comienzos del siglo XIII ${ }^{36}$.

El 31 de diciembre de 1203, el rey Pedro II el Católico (1196-1213), deseoso de establecer una abadía cisterciense femenina en su reino, adquiría de los monjes de San Juan de la Peña la iglesia de Santa María de Iguácel, para fundar junto a ella un monasterio de monjas bernardas, a cambio de dar, en compensación a la

34A. Ubieto Arteta (1964), pp. 191-192 y 198-199.

$35 \mathrm{Si}$ el interés inicial por esta pequeña iglesia románica de la diócesis de Jaca se debe al norteamericano

A. Kingsley Porter (1928), pp. 115-127, trabajos posteriores de investigación, de estudiosos españoles y franceses, fueron matizando y detallando aspectos de su arquitectura y decoración escultórica monumental. Todos ellos, a pesar de algunas discrepancias metodológicas, han señalado la importancia de este monumento de la segunda mitad del siglo XI, íntimamente relacionado con la monarquía aragonesa y con los maestros de la Seo de Jaca. M. Gómez Moreno (1934), p. 77; G. Gaillard (1938), pp. 121-124; A. Canellas López y A. San Vicente Pino (1971), pp. 165-189.

36A. Durán Gudiol (1973), pp. 205-208, A. I. Lapeña Paul (1989), pp. 300-301. 
abadía pinatense a la que pertenecía y a su abad Fernando, el monasterio de San Juan de Matidero con sus pertenencias ${ }^{37}$.

A Iguácel acudieron monjas del monasterio cisterciense de Morimond (Haute-Marne), que seguían bajo la autoridad del propio abad, don Enrique. Y el mismo monarca, estando en Barbastro en el año 1208, otorgaba, con la fundación, los diezmos de Senegüé y su honor y el heredamiento de Cambrón, junto a Sádaba, en la provincia de Zaragoza ${ }^{38}$.

En Iguácel las monjas no permanecieron mucho tiempo. Así, en 1212, motivadas por los rigores del clima invernal y la soledad del lugar, decidieron trasladarse a tierras más meridionales y mejor comunicadas, fijando su nueva residencia en una de las posesiones otorgadas con su fundación, la heredad de Cambrón (Zaragoza), para ser tuteladas por una comunidad cisterciense masculina, la del monasterio de Santa María de Veruela, al pie del Moncayo $^{39}$.

Desde 1245, Iguácel aparece en los repertorios eclesiásticos como iglesia propia de San Juan de la Peña, uniendo su biografía, de nuevo, a la del cenobio pinatense ${ }^{40}$.

De la iglesia de Santa María de Iguácel procede una importante obra de arte mueble que permanecía oculta para los fieles hasta hace algunos años y su descubrimiento fortuito tuvo lugar al mismo tiempo que los murales góticos del siglo $\mathrm{xV}$ de su cabecera, con ocasión de la restauración del edificio que los contenía $^{41}$.

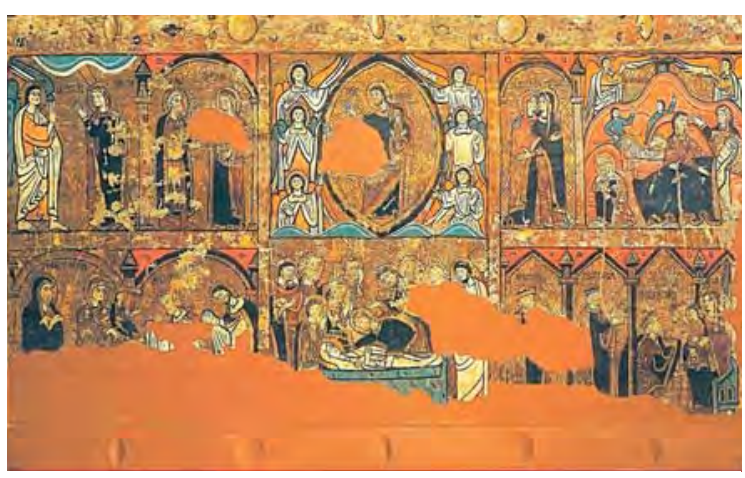

Frontal de Santa María de Iguácel (Huesca). Museo Diocesano de Jaca.

37 A. Canellas López (1987), pp. 59-63.

38 I. Martínez Buenaga (1973), pp. 183-188.

39 Las monjas permanecieron en Cambrón hasta finales del siglo xvi (1588), a excepción de una breve estancia de las religiosas en el convento de Santa María de Foris (extramuros de Huesca), entre 1454 y 1473; después de esa fecha se establecieron definitivamente en el monasterio de Santa María la Real de Zaragoza.

40A. Durán Gudiol (1973), p. 193.

41 M. ${ }^{a}$ C. Lacarra Ducay (1994), pp. 606-615. 
Se trata de un frontal de altar, pintado al temple sobre madera de pino ${ }^{42}$, obra de escuela pictórica altoaragonesa representativa de los inicios del estilo gótico lineal o francogótico, que cabe relacionar con la miniatura y la pintura mural de talleres locales en torno al año 1200.

Estaba vuelto del revés, sirviendo de tarima del altar que lo tuvo en sus ańos de gloria como frontal. Había pasado desapercibido por el sinnúmero de peregrinos que lo pisaron al visitar este solitario monumento, atraídos por sus capiteles tallados hacia 1072 por Galindo Garcés, que lo firmó. La resistencia física de esta bella tabla es otra prueba de la honradez profesional del hipotético taller jaqués ${ }^{43}$.

Descubierto en la primera fase de las obras de la restauración de la iglesia (1975-1983), se encuentra desde entonces por razones de seguridad en el Museo Diocesano de Jaca.

Está dedicado a exaltar la vida de la Virgen María, titular del santuario, con escenas dispuestas en dos pisos que abarcan desde la Anunciación a María y la Visitación a su prima Isabel, el Nacimiento en Belén, la Presentación en el templo y la Epifanía, hasta su Dormición y Asunción a los cielos con la recepción de su alma en forma de nińa en brazos de su hijo Jesucristo, como tema central de la obra.

Es un programa iconográfico poco habitual, como ya señalara Joan Sureda, al incluir entre las escenas de la Anunciación y la Visitación la inicial Duda de San José ante el embarazo de la Virgen María, procedente de los Evangelios Apócrifos, y al completar la escena del Nacimiento con el Anuncio a los pastores y con la presencia de dos comadronas, Zelomí y Salomé, citadas en el Evangelio del Pseudo Mateo (xIII, 3-5) 44 .

La ingenuidad de los modelos en los que se perciben ciertos convencionalismos del periodo románico precedente y el afán narrativo que refleja su artífice,

42 Pintura al temple sobre tabla $(95 \times 190 \mathrm{~cm})$. Restaurado hace algún tiempo, el deterioro afecta a la zona inferior del mueble.

43 W. W. S. Cook y J. Gudiol Ricart (1980), pp. 165-166.

$44 \mathrm{~J}$. Sureda (1985), pp. 380-381. El pasaje se describe en los Apócrifos de la Natividad como en el Protoevangelio de Santiago (xiII, 1-3) y en el Evangelio del Pseudo Mateo (x, 1-2). 
con la presencia de textos aclaratorios en las composiciones, le confieren un particular encanto.

Estilísticamente pertenece al mismo taller que dejará muestras de su valía en los muros de la cabecera de la ermita de San Juan Bautista de Ruesta y en el documento que hemos mencionado, copia de otro más antiguo conservado en la catedral de Jaca.

Respecto a su cronología parece oportuno datarlo, de acuerdo con su estilo, en la primera década del siglo XIII, y suponer que habría sido realizado, a instancias de la comunidad cisterciense femenina instalada en Santa María de Iguácel por iniciativa del rey Pedro II el Católico, el 31 de diciembre de 1203, que se preocupó de dotarla generosamente ${ }^{45}$.

45A esta misma conclusión, que compartimos, llegaron los autores que estudian el frontal en la obra colectiva: Non Meis Meritis, 1999, pp. 74-78. 


\section{Bibliografía}

AlcoleA, S. (1964): «El Maestro de Ruesta, nueva figura de nuestra pintura románica», Revista Goya, n. ${ }^{\circ}$ 62, Madrid, pp. 68-73.

- (1993): «Pinturas del ábside de Ruesta», en: Signos, Arte y Cultura en el Alto Aragón Medieval, Gobierno de Aragón-Diputación de Huesca, Huesca, pp. 288-291.

Almagro Gorbea, A. (1989-1990): «Restauraciones en el románico oscense: la iglesia de Santa María de Iguácel», Artigrama, n. ${ }^{\text {ss }}$ 6-7, pp. 49-79.

Borrás Gualis, G. M.; J. F. Esteban Lorente y M. García Guatas (1977): «La iglesia de Santiago de Ruesta en la ruta jacobea», en: Homenaje a don José María Lacarra de Miguel en su jubilación del profesorado, Estudios Medievales, I, Zaragoza, pp. 209-216.

Borrás Gualis, G.M. y M. García Guatas (1978): La pintura románica en Aragón. Investigaciones de Arte Aragonés, CAI / FGM, Zaragoza.

Canellas López, A. (1987): «El monasterio cisterciense zaragozano de Santa Lucía la Real, Iguacel, antepasado de Santa Lucía la Real», en: El Cister, órdenes religiosas zaragozanas, IFC, Zaragoza, pp. 59-63.

Canellas López, A. y A. San Vicente Pino (1971): Aragón Roman, Zodiaque, Paris.

Castiñeiras, M. (2010): «El románico catalán en el contexto hispánico de la Edad Media. Aportaciones, encuentros y divergencias", en: El esplendor del Románico. Obras maestras del Museu Nacional d'Art de Catalunya, Fundación Mafre, Madrid, pp. 47-69.

Cook, W. W. S. y J. Gudiol Ricart (1980²): Pintura e imaginería románicas, vol. VI de Ars Hispaniae. Historia Universal del Arte Hispánico, Plus Ultra, Madrid.

Durán Gudiol, A. (1962): La iglesia de Aragón durante los reinados de Sancho Ramírez y Pedro I (1062?1104), Iglesia Nacional Española, Roma.

- (1965): «La Santa Sede y los obispados de Huesca y Roda en la primera mitad del siglo XII», Antológicas Annua, n. ${ }^{\circ}$ 13, Roma, pp. 35-134.

- (1991): «Monasterios y monasteriolos en los obispados de Pamplona y Aragón en el siglo XI», en: Príncipe de Viana, año LII, n. ${ }^{\circ}$ 193, Navarra, pp. 69-88.

Durliat, M. (1982): L'Art Roman, Èditions d'Art Lucien Mazenod, Paris.

Gaillard, G. (1938): Les débuts de la sculpture romane espagnole: Leon, Jaca, Compostela, Paul Hartmann Éditeur, Paris.

Galtier Martí, F. (2006): «El marco histórico aragonés del beato de Fanlo», en: AA. vv., El beato del abad Banzo del monasterio de San Andrés de Fanlo, un Apocalipsis aragonés recuperado. Facsímil y estudio, Caja Inmaculada, Zaragoza, pp. 210-222.

García Guatas, M. (1993): «Lipsanoteca», en: Signos, Arte y Cultura en el Alto Aragón Medieval, Gobierno de Aragón-Diputación de Huesca, Huesca, p. 244.

- (1993): «Pinturas murales de la iglesia de Bagüés», en: Signos, Arte y Cultura en el Alto Aragón Medieval, Gobierno de Aragón-Diputación de Huesca, Huesca, pp. 246-251.

- (1993): «Fragmento de pintura de la iglesia de Vió», en: Signos, Arte y Cultura en el Alto Aragón Medieval, Gobierno de Aragón-Diputación de Huesca, Huesca, pp. 274-275.

Gómez Moreno, M. (1934): Arte románico español, esquema de un libro, Publicaciones del Centro de Estudios Históricos, Madrid.

Gudiol Ricart, J. (1971): Pintura medieval en Aragón, Institución Fernando el Católico, Zaragoza. 
Huesca, P. Ramón de (1797): Teatro histórico de las Iglesias del Reyno de Aragón, vol. vi, Pamplona.

Kingsley Porter, A. (1928): «Iguacel and more Romanesque Art of Aragón», en: The Burlington Magazine, I, 1928, pp. 115-127.

LACARra, J. M. a (1978): Alfonso I el Batallador, Guara Editorial, Zaragoza.

Lacarra Ducay, M. a C. (1993): Catedral y Museo Diocesano de Jaca, IberCaja, Ediciones Ludion y Marot, Bruselas.

- (1994): «Las pinturas murales góticas de Santa María de Iguacel (Huesca)», en: Anales de la Historia del Arte, n. ${ }^{\circ}$ 4, Homenaje al Prof. Dr. D. José M. a de Azcárate, Editorial Complutense, Madrid, pp. 605-615.

- (2000): «Arte en el Monasterio Medieval de San Juan de la Peña, Arquitectura y pintura», en vv. AA., San Juan de la Peña. Suma de Estudios I, Mira Editores, Zaragoza, pp. 51-63.

- (2010): Estudio histórico de la decoración mural interior de San Esteban de Almazorre, Prames, Zaragoza.

- (2010): «El mecenazgo real en los siglos XIII, XIV y xv, en Reyes de Aragón. Soberanos de un País con futuro. Ramiro I - Juan Carlos I (1035-2011), Ibercaja, Obra Social, Gobierno de Aragón, Zaragoza, pp. 335-338.

Laliena Corbera, C. (1996): La formación del estado feudal. Aragón y Navarra en época de Pedro I, Colección de Estudios Altoaragoneses, 42. Instituto de Estudios Altoaragoneses, Huesca.

Lapeña Paul, A. I. (1989): El monasterio de San Juan de la Peña en la Edad Media (desde sus origenes hasta 1410), CAI, Zaragoza.

— (1993): «Donación de Ramiro I y su hijo Sancho a San Pedro de Jaca», en: Signos, Arte y Cultura en el Alto Aragón Medieval, Gobierno de Aragón-Diputación de Huesca, Huesca, pp. 292-293.

Martínez Buenaga, I. (1973): «El monasterio cisterciense femenino de Cambrón», en: El Cister, órdenes religiosas zaragozanas, IFC, Zaragoza, pp. 183-193.

Sureda Pons, J. (1985): La pintura románica en España, Alianza Editorial, Madrid.

Ubieto Arteta, A. (1973) «El románico de la catedral jaquesa y su cronología», en: Príncipe de Viana, año 25, n. ${ }^{\text {os }} 96$ y 97 , pp. $187-200$.

VV.AA. (1999): Meis Meritis. Guía y estudio critico de la ermita de Santa María de Iguácel, Colección Egido Universidad, n. ${ }^{\circ} 20$, Zaragoza.

Wettstein, J. (1978): La fresque romane. La route de Saint-Jacques, de Tours à Leon. Études comparatives II, Arts et Métiers Graphiques, Paris. 